УДК 537.633

\title{
Properties of Magnetorheological Elastomers in Crossed AC and DC Magnetic Fields
}

\author{
Yuliya A. Alekhina* \\ Ludmila A. Makarova ${ }^{\dagger}$ \\ Tatyana S. Rusakova ${ }^{\ddagger}$ \\ Anna S. Semisalova ${ }^{\S}$ \\ Nikolay S. Perov \\ Department of Physics \\ Lomonosov Moscow State University \\ 119991, Moscow \\ Russia
}

Received 06.08.2016, received in revised form 06.09.2016, accepted 16.11.2016

\begin{abstract}
Dynamic properties of magnetorheological elastomers (MREs) with barium ferrite particles in the presence of crossed AC and DC magnetic fields were investigated. Calculations of the magnetic permeability were made based on the fact, that the inductance of the coil changes when the coil is filled with the elastomer. Measurements of inductances of an empty coil and the coil with elastomeric core were carried out. The core was smaller than the space inside the coil, so it was able to move within the coil. The dependencies of real and imaginary parts of magnetic permeability on AC field frequency had resonance peaks at different values of DC magnetic field strength. The sample vibration was considered in frame of the elastic rod oscillations model. The change of dielectric permittivity of the elastomer with conductive particles under magnetic field (so-called magnetodielectric effect) was also investigated. These effects are the examples of transformation of the magnetic field energy into the electrical or mechanical energy of the MRE.

Keywords: magnetorheological elastomers, mechanical resonance, sonic frequency, magnetodielectric effect.

DOI: $10.17516 / 1997-1397-2017-10-1-45-50$.
\end{abstract}

\section{Introduction}

Magnetorheological elastomers, which represent an elastic polymer medium filled with magnetic particles, captured a great interest for scientific and practical research. Under magnetic field they can demonstrate effects which characteristics can be controlled by varying the parameters of the elastomer (namely, material and size of the filler particles, elasticity of the matrix, etc.) or the magnetic field parameters.

The elastomers have a variety of applications in systems with oscillating units. Due to the elasticity of the carrier matrix and the interaction of the magnetic component of the elastomers with the external magnetic field they can be used as elements with variable stiffness. The natural frequency of oscillations can be shifted by applying the external magnetic field [1-5]. The elastomers can also be utilized as an oscillating element. In [6] it was demonstrated, that

\footnotetext{
*yu.alekhina@physics.msu.ru

†la.loginova@physics.msu.ru

ts.rusakova@physics.msu.ru

$\S$ semisalova@physics.msu.ru

『perov@physics.msu.ru

(c) Siberian Federal University. All rights reserved
} 
the natural frequency of oscillations of the elastomer with iron particles was about 20-30 $\mathrm{Hz}$. For the higher frequencies, the parameters of the elastomer should be changed. In this work, the investigation of the resonance effects in the elastomers at sonic frequencies was carried out.

Under magnetic field the change of dielectric permittivity of the elastomer (so-called magnetodielectric effect) can also be observed [7].

The above-mentioned effects are the examples of transformation of the magnetic field energy into the electrical or mechanical energy of the MRE, which allow to construct converters and actuators. Variation of the resonance frequency with changes in external conditions can be used in working principles of various types of wireless detectors, absorbers and modulators of electromagnetic waves at sonic frequencies.

\section{Materials and methods}

Samples of the magnetorheological elastomers used in this work were prepared at SSC RF GNIIChTEOS by Stepanov G.V. on the basis of two-component silicone compound SIEL. Filler concentrations was $56 \mathrm{wt} . \%$ and $80 \mathrm{wt} . \%$ for the elastomers with carbonyl iron particles and $61 w t . \%$ for the elastomers with barium ferrite particles.

For the capacitance measurements, the sample was placed between the plane capacitor plates and then fixed between the electromagnet poles so that the plates were perpendicular to the magnetic field direction (Fig. 1a).

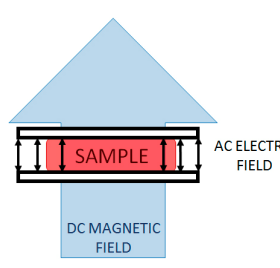

(a)

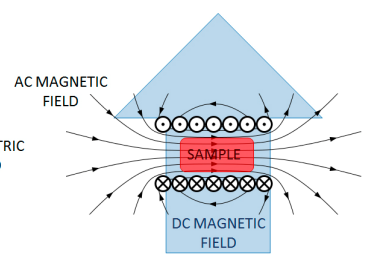

(b)

Fig. 1. Scheme of the capacitance (a) and inductance (b) measurements

The value of the magnetic permeability can be obtained from the inductance of the coil with the core changing. The coil was placed into the polymer clay cube to prevent it from the oscillation and to fix it inside the electromagnet. The sample was placed into the coil, and then the coil was placed between the poles of the electromagnet (Fig. 1b).

Measurements of the inductance and capacitance were carried out using the immitancemeter Aktakom AM-3016.

The real and imaginary parts of magnetic permeability can be approximately calculated the following way:

and

$$
\mu^{\prime}=\frac{Q}{Q_{0}}+Q \mu^{\prime \prime}
$$

$$
\mu^{\prime \prime}=\frac{\frac{Q^{2}}{Q_{0}} \pm \sqrt{\frac{Q^{4}}{Q_{0}^{2}}-\left(Q^{2}+1\right)\left(\frac{L_{0}^{2}}{L^{2}}-\frac{Q^{2}}{Q_{0}^{2}}\right)}}{\left(Q^{2}+1\right)}
$$

Where $Q_{0}$ and $Q$ are quality factors of a circuit with coil $L_{0}$ or $L$. Here $L_{0}$ and $L$ are inductances of an empty and cored coil. The expression does not take the filling coefficient of the coil into account, thus the quantitative comparison is impossible. However, accounting the filling coefficient does not change the shape of the inductance curve and resonance frequencies. For this reason, these formulas can be used for qualitative verification of the resonance existence and resonance frequencies estimation. 


\section{Results and discussion}

Under DC magnetic field the elastomer with iron particles demonstrated the magnetodielectric effect [6] (Fig. 2). Moreover, the capacity was frequency independent and should not be taken into account in inductance measurements

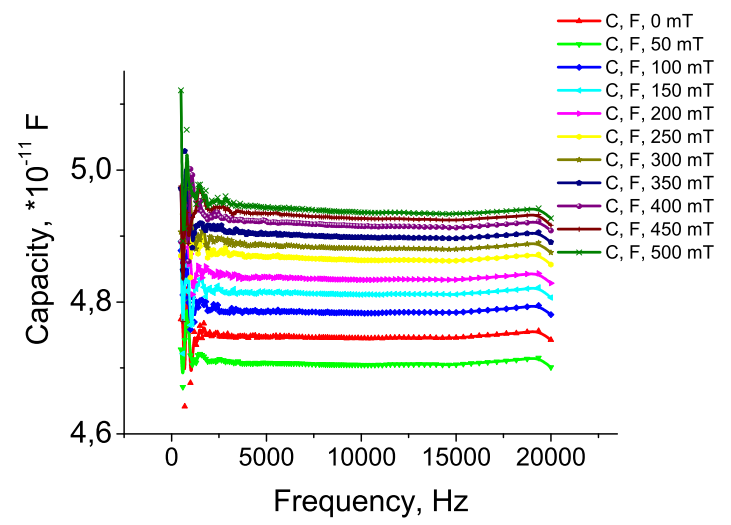

Fig. 2. The dependence of capacity of the elastomer filled capacitor on frequency

The effect of the AC magnetic field on the filler particles (and therefore the whole elastomer) is periodical and can lead to the mechanical oscillations and resonance excitation. Such resonance, which can be described by the elastic rod oscillation model, can occur in the elastomers with nonconductive particles in crossed AC and DC magnetic fields. Magnetic moments of the filler particles line up along the field direction and their interaction changes. Due to the elasticity of the carrier matrix, the length of the sample along the field direction changes and it returns the initial value when the current passes through zero. When the current changes the direction the magnetic moments of the particles also turn to another direction.

In case of conductive particles with the change of the magnetic field strength Foucault currents are induced, which anticipate the magnetic flux change, thus, the effective AC field applied to the elastomer is practically tend to zero. For this reason, at high frequencies of the AC field the elastomers with conductive particles do not demonstrate resonance energy absorption (Fig. 3).

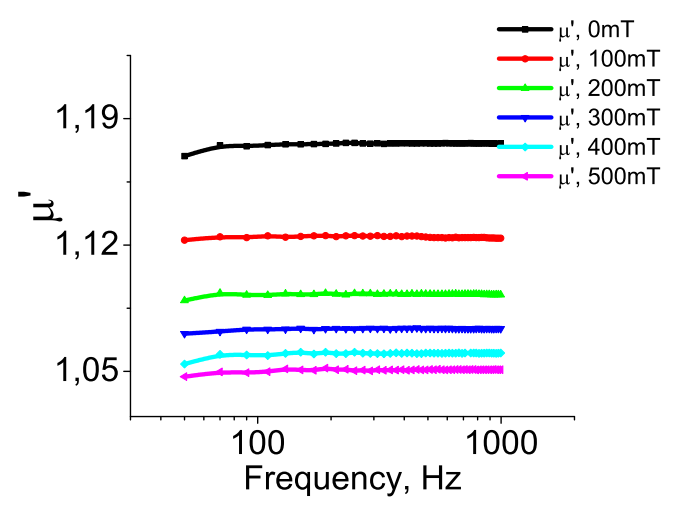

Fig. 3. The real part of the magnetic permeability of the elastomer with iron particles

When the elastomer with Barium ferrite particles at the concentration of $61 \mathrm{wt} . \%$ was placed into the coil and the diameters of a coil and the elastomer core were the same, frequency de- 
pendencies of the real and imaginary parts of permeability did not have any resonance parts (Fig 4).

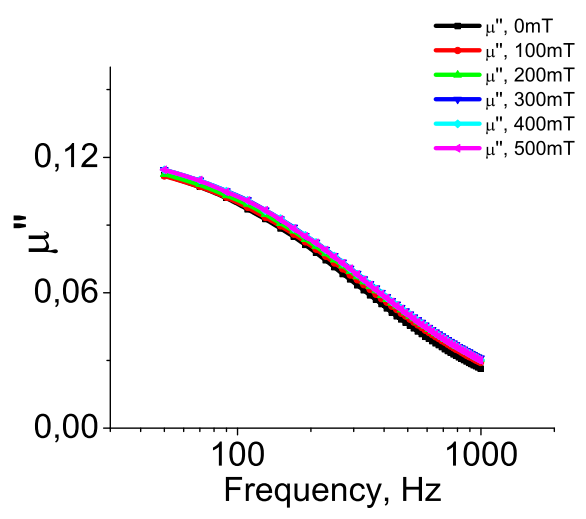

Fig. 4. The imaginary part of the magnetic permeability of the elastomer with barium ferrite particles. The elastomer takes the whole place inside the coil

In case of the elastomer freely placed into the coil the experimental dependencies of the real and imaginary parts of permeability had resonance peaks (Fig. 5).

Such a way of placing the core gives it the ability to move inside the coil. Moreover, magnetorheological effect (the increase of the Young's modulus with the magnetic field strength increase) leads to the shifting of the resonance frequency with magnetic field value.
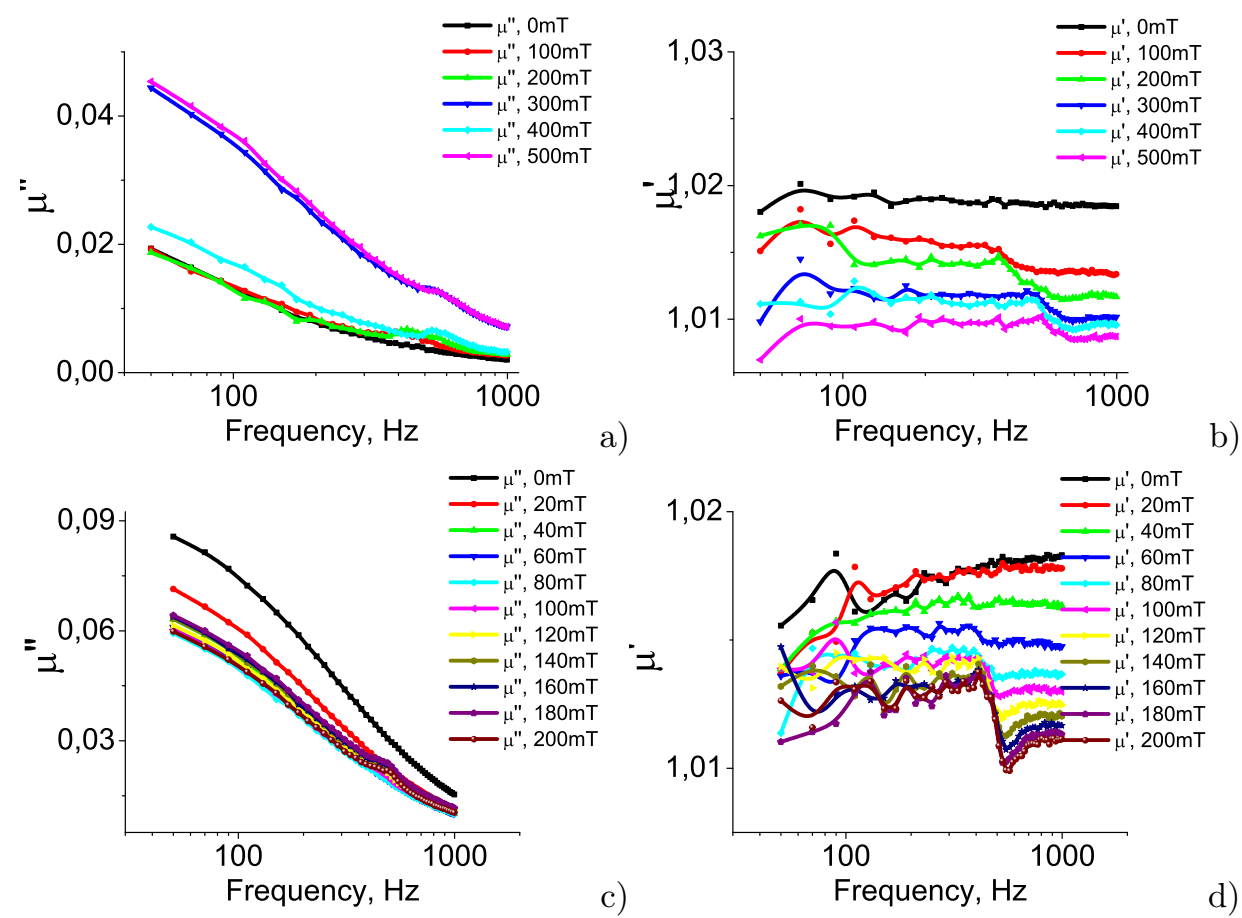

Fig. 5. The imaginary $(\mathrm{a}, \mathrm{c})$ and real $(\mathrm{b}, \mathrm{d})$ parts of the magnetic permeability of the elastomer with barium ferrite particles 
Analytical calculation proves the existence of the natural frequencies in the range of experimentally observed resonance frequencies.

II Newton's law for the rod part with a length dx leads to an equation of oscillations:

$$
u_{t t}=a^{2} u_{x x}
$$

where $a=\sqrt{\frac{E}{\rho}}, u(x, t)$ is the displacement of the transverse section, $E$ is Young's modulus, $\rho$ is density. The natural frequencies are $\omega=\frac{\pi a n}{l}$ and $\omega_{0}=\frac{\pi a}{l}$, where $l$ is length of the rod, $n$ is harmonic number. The resonance frequencies on the experimental curves are also multiple, which proves the reliability of the model.

For the values $E=10^{4}-10^{5} \mathrm{~Pa}, \rho=1800 \mathrm{~kg} / \mathrm{m}^{3}, l=2.3 \mathrm{~cm}$ the first natural frequency was in the range of $50-200 \mathrm{~Hz}$.

For the elastomers with barium ferrite particles at the same concentration but with larger value of matrix stiffness resonance peaks on the curves of the imaginary and real parts of magnetic permeability were not observed.

\section{Conclusion}

The mechanical resonance effect can be observed in the elastomers with nonconductive particles in crossed AC and DC magnetic fields. The capacitance change with frequency can be ignored. The resonance peaks, which were observed for the samples of the elastomer with barium ferrite particles, depend on the magnetic field strength, sample size, matrix elasticity. These dependencies can be explained by the mechanical oscillation of the sample, which can be described by the elastic rod oscillation model: the sample changes the length with the change of AC magnetic field. The experiment also confirms the existence of multiple frequencies, which were predicted by the model.

\section{References}

[1] Li.Yancheng, Li.Jianchun, Li.Weihua, Du.Haiping, A state-of-the-art review on magnetorheological elastomer devices, Smart Materials and Structures, 23(2014), 1-31.

[2] J.G.Ding, Z.Qiao, C.C.Zhou, Study on the performance of magnetorheological elastomers and engineering application, Materials Research Innovations, 19(2015), no. S8, 168-173.

[3] J.S.Ubaidillah, P.Agus, A.M.Saiful, Recent Progress on Magnetorheological Solids: Materials, Fabrication, testing, and Applications, Advanced engineering materials, 17(2014), 563-597.

[4] J.Yang, S.S.Sun, H.Du, W.H.Li, G.Alici, H.X.Deng, A novel magnetorheological elastomer isolator with negative changing stiffness for vibration reduction, Smart materials and structures, 23(2014), 1-11.

[5] Shuaishuai Sun, Huaxia Deng, Jian Yang, Weihua Li, Haiping Du, Gursel Alici, Masami Nakano, An adaptive tuned vibration absorber based on multilayered MR elastomers, Smart materials and structures, 24(2015), 1-13.

[6] S.Abramchuk, E.Kramarenko, G.Stepanov, L.V.Nikitin, G.Filipcsei, A.R.Khokhlov, M.Zrinyi, Novel highly elastic magnetic materials for dampers and seals: part II. Material behavior in a magnetic field, Polymers for advanced technology, 18(2007), 513-518. 
[7] A.S.Semisalova, N.S.Perov, G.V.Stepanov, E.Yu.Kramarenko, A.R.Khokhlov, Strong magnetodielectric effects in magnetorheological elastomers, Soft Matter, 47(2013), no. 9, 1131811324.

\title{
Свойства магнитореологических эластомеров в скрещенных переменном и постоянном магнитных полях
}

\author{
Юлия А. Алехина \\ Людмила А. Макарова \\ Татьяна С. Русакова \\ Анна С. Семисалова \\ Николай С. Перов \\ Физический факультет \\ МГУ имени М.В.Ломоносова \\ Ленинские горы, 1/2, Москва, ГСП-1, 119991
}

Россия

В работе были исследованы динамические свойства магнитореологических эластомеров (МРЭ) c частицами феррита бария в скрещенных переменном и постоянном магнитных полях. Магнитная проницаемость МРУ была измерена индуктивным методом. При этом эластомерный сердечник измерительной катушки не полностью заполнял пространство внутри катушки и имел возможсноть двигаться. На зависимостях действительной и мнимой частей магнитной проницаемости от частоты переменного поля присутствуют резонансные пики. Этот эффект рассматривался в рамках модели продольных колебаний упругого стержня.

В работе также представлены результаты измерения диэлектрической проничаемости МРЭ с проводящими частицами в магнитном поле (так называемый магнитодиэлектрический эффект).

Ключевые слова: магнитореологические эластомеры, механический резонанс, переменное магнитное поле, магнитодиэлектрический эффект. 